\title{
GESTÃO DO PROCESSO DE DESENVOLVIMENTO DE PRODUTO: ESTUDO DE CASOS EM EMPRESAS NACIONAIS FABRICANTES DE MÁQUINAS AGRICOLAS
}

\author{
Aline Patrícia Mano ${ }^{1}$ \\ José Carlos de Toledo
}

\begin{abstract}
Resumo: A indústria de Máquinas e Implementos Agrícolas (MIAs) apresenta grande potencial de crescimento no país, acompanhando a expansão do setor agroindustrial brasileiro e focando no aumento da exportação de seus produtos. Como alternativa para atingir um faturamento melhor distribuído ao longo do ano, busca-se superar os problemas da sazonalidade e da instabilidade da demanda interna aumentando a exportação e se capacitando para melhor enfrentar a perspectiva de maior presença de empresas multinacionais no país. Isso exige das empresas nacionais uma melhoria na competitividade, tanto no projeto de novos produtos quanto na manufatura, adequando-se a padrões de desempenho internacionais e à tendência de exigências de homologação dos novos produtos. Essa melhoria passa por uma revisão e adequação do processo de desenvolvimento de produto, e de sua gestão, nas empresas nacionais do setor. Este trabalho apresenta uma análise das práticas e dos problemas da gestão do processo de desenvolvimento de produtos em cinco empresas nacionais de grande porte, do setor, localizadas no estado de São Paulo. Ainda que haja diferenças entre as empresas, o grau de maturidade do PDP, de modo geral, encontra-se em nível básico.
\end{abstract}

Palavras-chave: Desenvolvimento de produtos; Máquinas e implementos agrícolas; Gestão do processo de desenvolvimento de produto.

\begin{abstract}
The industry of Agricultural Implements and Machines has had an expressive development in the country, following the expansion of the Brazilian agro-industrial area and focusing in the exportation increase of the agricultural products as alternative to reach a better distributed invoicing throughout the year, being tried to overlap the problems of the internal seasonality. It demands from the national companies a quality improvement of the projects and manufacture of these products, adjusting them to international standards of performance and to the trend of homologation requirements of the new products. This improvement passes for a revision and adequacy of the product development process management in the sector's national companies. This work presents a research about the practices and problems of the management of the process development of the agricultural products from five national companies located in the Sao Paulo state. To sum up, it was verified that the maturity degree of PDP's nationals companies is low.
\end{abstract}

Keywords: Product Development; Agricultural Implements and Machines; Management of Product Development Process.

\footnotetext{
1 Universidade Estadual de Santa Cruz/ Departamento de |Ciencias Exatas e Tecnológicas. Rodovia Ilheus Itabuna Km 16 CEP 45662-900, Ilheus- BA- Brasil. alinepatricia07@hotmail.com

2 Universidade Federal de São Carlos/ Departamento de Engenharia de Produção. Rod. Washington Luiz, km 235 - CEP $13565-$ 905, Caixa Postal 676 - São Carlos-SP - Brasil. toledo@dep.ufscar.br
} 


\section{INTRODUÇÃO}

O mercado de máquinas agrícolas tem apresentado, no final da primeira década do século XXI, grandes oportunidades de crescimento para as empresas nacionais que desenvolvem e manufaturam equipamentos para o setor. No entanto, as grandes empresas mundiais do setor identificaram essa perspectiva no país e vêm, cada vez mais, introduzindo seus produtos no mercado brasileiro, com implicaçôes na competitividade e na participação no mercado. Isso tem exigido melhor capacitação no processo de desenvolvimento de produtos (PDP) das empresas dessa cadeia de produção.

A dinâmica do PDP em mercados competitivos exige que as empresas desenvolvam novos produtos em curtos espaços de tempo e com o mínimo de problemas de qualidade do projeto, que tendem a se manifestar na manufatura e nos primeiros meses de uso do equipamento, comprometendo a imagem do novo produto e da marca.

Busca-se reduzir os retrabalhos e custos requeridos pelas eventuais mudanças em projetos, combinado com uma estratégia de lançar novos produtos com uma maior freqüência. Entretanto, o lançamento de um produto, por si, não garante que este obterá sucesso no mercado. É necessário que o novo produto satisfaça as reais necessidades dos clientes, em todas as fases do ciclo de vida do produto.

Segundo Romano (2003), a indústria brasileira de máquinas e equipamentos agrícolas tem demonstrado dificuldades na gestão do PDP, já que as atividades de desenvolvimento são realizadas informalmente, apresentando deficiências e falhas ao longo de todo o processo de desenvolvimento.

A gestão do PDP é uma atividade complexa e dinâmica, compreendendo atividades de projeto e de manufatura até de gestão de recursos e informações, percorrendo desde o levantamento das necessidades do mercado até a decisão de retirada planejada do produto do mercado. Segundo Rozenfeld et al. (2006), o PDP pode ser caracterizado por um conjunto de atividades que se iniciam com o levantamento das necessidades do mercado e das possibilidades e restrições tecnológicas, que servem de entrada para as etapas seguintes de especificação do projeto do produto e do processo de manufatura, considerando a estratégia competitiva da empresa.
O objetivo deste trabalho é caracterizar a gestão do PDP em uma amostra de empresas nacionais de grande porte produtoras de máquinas e implementos agrícolas, localizadas no estado de São Paulo, classificando-as quanto ao grau de maturidade do PDP. No Estado de SP existem cinco empresas nacionais de grande porte que desenvolvem e manufaturam máquinas e implementos agrícolas. O PDP dessas cinco empresas é o objeto de estudo deste trabalho. A pesquisa de campo é desenvolvida por meio da estratégia de estudo de casos múltiplos.

\section{A INDÚSTRIA DE MÁQUINAS E IMPLEMENTOS AGRÍCOLAS}

A indústria de máquinas e implementos agrícolas enfrenta mudanças constantes no ambiente de mercado, pois sofre influencia direta da produção e das atividades agrícolas, que são dependentes de condiçôes ambientais tais como do clima, dos preços relativos, da oferta mundial de produtos agrícolas, além das condições de juro e de financiamento para aquisição desses equipamentos.

A inovação e modernização desta indústria acompanham a dinâmica da inovação do setor agropecuário (Molin, 2001). Os primórdios da mecanização agrícola mundial ocorreram em países caracterizados por grandes propriedades, como foi, por exemplo, o caso dos EUA, que também é caracterizado por freqüentes e vultosos subsídios governamentais. Isto sinaliza, desde o início, as dificuldades técnicas e econômicas que as pequenas propriedades enfrentam para evoluírem de um sistema de produção intensivo em mão-de-obra para uma produção mecanizada (NOGUEIRA, 2001).

No Brasil o setor de MIAs apresenta uma estrutura muito heterogênea, com a presença desde empresas multinacionais de grande porte até de pequenas empresas nacionais de administração familiar.

Os produtos desse setor podem ser divididos em dois grandes grupos: tratores e equipamentos; máquinas e implementos agrícolas. Dentro desses grupos os produtos são classificados segundo a atividade agrícola para qual se destinam, conforme Gadanha et al (1991):

- Tipo 1: Tratores e motores;

- Tipo 2: Preparo do solo; 
- Tipo 3: Semeadura, plantio e adubação;

- Tipo 4: Cultivo;

- Tipo 5: Aplicação de defensivos agrícolas;

- Tipo 6: Colheita de produtos agrícolas;

- Tipo 7: Transporte, elevação e manuseio dos cultivos colhidos;

- Tipo 8: Processamento e armazenamento.

Trata-se de um setor com características muito particulares. A demanda apresenta uma variação muito alta durante o ano; a estratégia comum de terceirização da produção de componentes e peças enfrenta dificuldade quanto à capacitação dos fornecedores; baixo volume de produção, por tipo e modelo de produto, e uma demanda focada em produtos customizados a regiōes do país e aos perfis das propriedades rurais país.

De modo geral o mercado de MIAS é tão instável quanto à comercialização de produtos agrícolas. Considerando-se o conceito de cadeia industrial e compreendendo que a indústria de MIAs esta inserida na cadeia produtiva agroindustrial brasileira, esta instabilidade não é surpreendente.

\section{O DESENVOLVIMENTO DE NOVOS PRODUTOS E SUA GESTÃO}

Segundo Rozenfeld et al (2005), o desenvolvimento de um novo produto ocorre por meio de um processo de negócio, o PDP, que tem inicio com a identificação de uma necessidade ou oportunidade de mercado que, posteriormente, é transformada em um novo produto. Para que isso ocorra é necessário compreender e traduzir as necessidades do mercado, identificar as possibilidades e limitações tecnológicas e gerar as especificações de projeto do produto e do seu processo de manufatura. Paralelamente a essas atividades ocorre o planejamento para lançar o produto no mercado. Após o lançamento do mesmo é responsabilidade do PDP atentar para o desempenho do novo produto, no uso e na produção, realizando, quando necessário, mudanças nas especificações, até a fase de descontinuidade planejada do produto no mercado.

Algumas especificidades deste processo são: o elevado grau de incertezas relacionado ao processo; administração de muitas informações provenientes de diferentes fontes, como clientes, fornecedores e das diversas áreas da empresa e; diversidade de requisitos que o projeto de um novo produto deve atender, considerando os requisitos dos clientes, a capacidade da manufatura produzir o produto projetado, os serviços de assistência técnica necessários e a reciclagem no fim do ciclo de vida do produto.

De acordo com Clark e Fujimoto (1991), uma organização que vise ter competitividade com um novo produto deve focar, durante o processo de desenvolvimento, em metas e indicadores baseados em tempo de conclusão do projeto, na qualidade do projeto, no custo do desenvolvimento do produto e na adequação entre o custo do produto do desenvolvido e seu custo alvo.

O bom desempenho do PDP, segundo Clark e Wheelwright (1992), depende de características de gestão deste processo tais como: ter os objetivos do projeto bem definidos, foco no tempo e no mercado, integridade do projeto, integração entre as áreas funcionais da empresa envolvidas no projeto, realização de protótipos de alta qualidade, robustez das informações e decisões e forte liderança nas equipes que realizam as atividades do projeto. Busca-se, por meio dessas características de gestão, um processo de desenvolvimento eficaz e eficiente, que resulte em produtos e processos competitivos.

O PDP de uma empresa apresenta algumas fases básicas que são comuns a todos os projetos, porém cada projeto tem suas fases tratadas de maneira individual. De acordo com Rozenfeld et al (2005), as atividades do PDP podem ser agrupadas em três macro-fases: Pré-desenvolvimento; Desenvolvimento; Pós-desenvolvimento. O pré-desenvolvimento consiste no planejamento estratégico do produto e no planejamento do projeto, por meio de avaliações das estratégias de mercado e tecnológicas da empresa.

Durante a etapa de desenvolvimento objetiva-se estabelecer as especificações de projeto do produto e do processo de manufatura, ou seja, encontrar soluções para o problema (necessidade e requisitos do projeto) a ser resolvido. O pós-desenvolvimento engloba atividades relacionadas ao acompanhamento do desempenho do produto no mercado e na produção, da satisfação do cliente com o novo produto, identificação da necessidade de mudanças e, em alguns casos, também se planeja a retirada do produto do mercado. A Figura1 apresenta essas fases. 


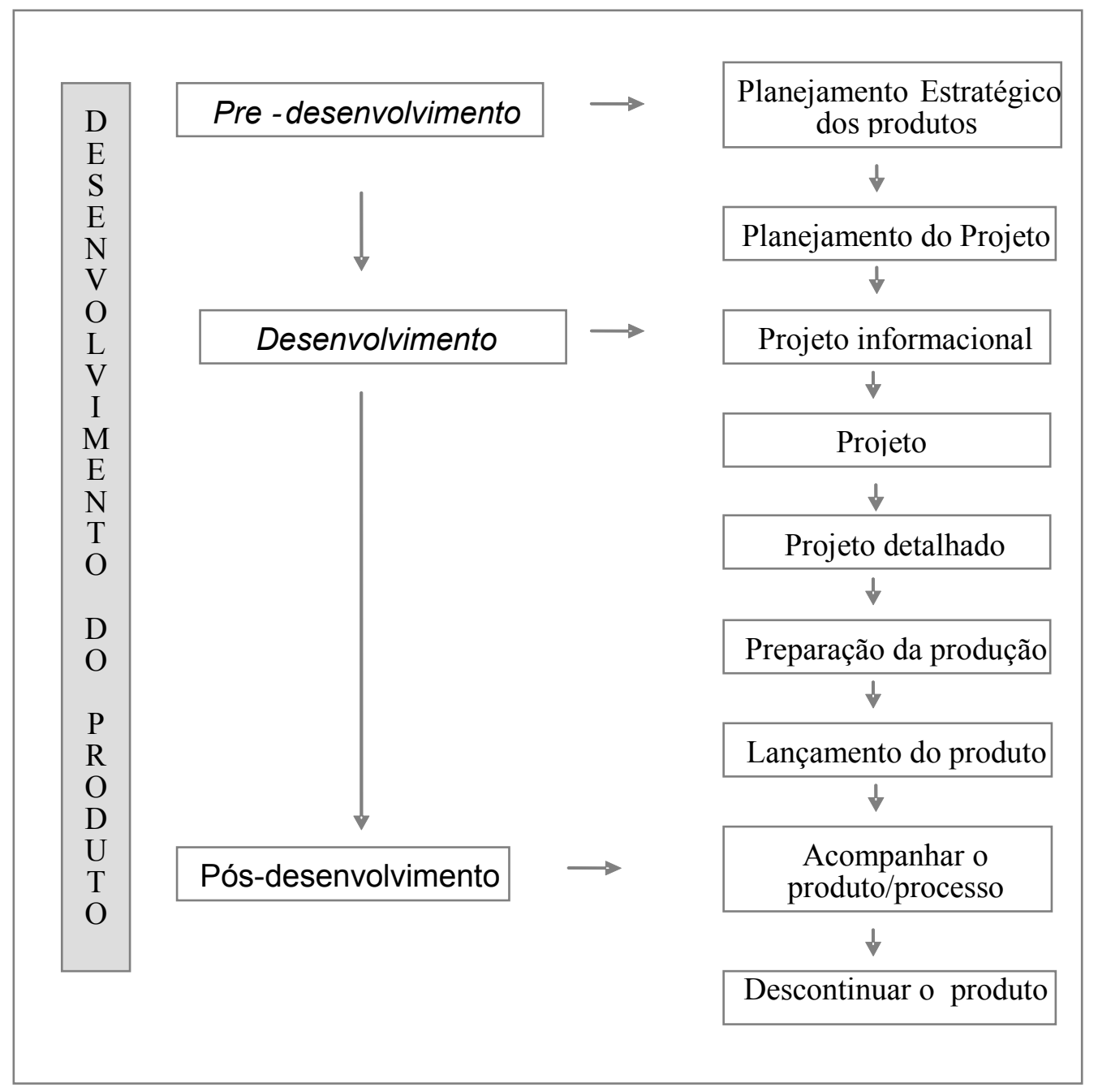

Figura 1 - Fases do PDP. FONTE: adaptado de Rozenfeld et al (2005)

A medição de desempenho é importante para a gestão do PDP enquanto ferramenta de apoio à gestão do processo, fornecendo informação que facilitam o processo de tomada de decisões.

De acordo com Driva et al (2000) os principais indicadores de desempenho utilizados no PDP são: - Tempo total de desenvolvimento, de quando surge uma nova idéia até o lançamento no mercado; - Grau de compreensão das necessidades dos clientes; - Estagio atual do projeto em comparação com o planejamento do mesmo; Comparação entre a qualidade do produto e qualidade desejada; - Número de falhas do projeto detectadas pelo cliente; - Custo total do projeto; Flexibilidade (tempo para cumprir mudanças em projetos por solicitações especificas dos clientes) Segundo Brown e Eisenhardt (1995) e Cooper e Kleinschmidt (1995), os principais fatores de organização e gestão que afetam diretamente o desempenho do PDP são:
- Equipe de projeto: a Equipe é responsável por transformar a informação do mercado em informação para a produção industrial. Em relação à formação da equipe, existem fortes indícios de que a interdisciplinaridade e a afinidade dos membros afetam de maneira positiva a atuação da equipe e, conseqüentemente, o desempenho do PDP.

- Liderança das equipes de projeto: Os lideres do projeto representam o elo de ligação entre a equipe de projeto e a alta administração da empresa. Sua atuação afeta o desempenho da equipe, em função de sua capacidade requerida para solucionar conflitos, assegurar os recursos necessários ao projeto e um bom ambiente de trabalho, mantendo na equipe uma visão de longo prazo sobre os rumos que o projeto deve seguir. 
- Envolvimento de fornecedores: o envolvimento dos fornecedores pode diminuir o lead time do projeto, aumentando a produtividade por meio da diminuição da complexidade do projeto e da antecipação de problemas de projeto por parte da equipe de desenvolvimento de fornecedores.

- Envolvimento de clientes: o envolvimento dos clientes pode resultar em uma melhora no conceito do produto.

De acordo com Rozenfeld et al. (2005), é possível classificar o grau de maturidade em que se encontra o PDP de uma empresa com base nas atividades que a empresa realiza, nas ferramentas utilizadas para realização das mesmas, e no uso dos conceitos de melhoria continua. Considera-se cinco níveis gerais de maturidade para o PDP:

- Básico: realização de poucas atividades relativas ao PDP;

- Intermediário: as atividades do PDP são padronizadas e são utilizadas ferramentas de apoio às mesmas;

- Mensurável: além das atividades realizadas no nível intermediário, utiliza-se indicadores de desempenho para medir os resultados obtidos em cada atividade;

- Controlado: com base nos indicadores a empresa trabalha em prol de corrigir os erros ou desvios da situação desejada;

- Melhoria contínua: a empresa busca permanentemente melhorar seu PDP.

\section{MÉTODO DE PESQUISA}

O método de pesquisa adotado consistiu, primeiramente, na realização de uma revisão bibliográfica sobre a industria nacional de máquinas e implementos agrícolas e sobre o processo de desenvolvimento de produtos e sua gestão.

São muitas e complexas as variáveis envolvidas na gestão do PDP, conforme exposto na revisão bibliográfica, com base neste conhecimento teórico foi elaborado um questionário para levantamento de informaçōes sobre a gestão do PDP nas empresas objeto da pesquisa. $\mathrm{O}$ questionário abordou questões sobre: estrutura e recursos de desenvolvimento de produto; práticas de gestão do PDP; práticas de organização das equipes de projeto; uso de métodos e técnicas de apoio ao PDP; e uso de métodos e técnicas de apoio ao PDP.
O questionário foi aplicado por meio de visitas e entrevistas pessoais, junto ao responsável pelo desenvolvimento de produto das cinco empresas nacionais, consideradas de grande porte (com mais de 500 funcionários), localizadas no estado de São Paulo.

\section{DESCRIÇÃO E ANÁLISE DOS DADOS}

\subsection{PERFIL DAS EMPRESAS}

Para apresentação dos dados levantados as empresas serão denominadas por A, B, C, D e E.

Apesar de serem empresas consideradas de grande porte, há predominância do modo de administração familiar entre essas empresas. Porém esta prática encontra-se em mudança, visto que atualmente uma empresa já tem consolidada a administração profissional (C) e duas empresas ( D e E) estão em transição, migrando para uma administração profissional.

Todas as empresas atuam em maior intensidade no mercado nacional. Nas empresas A, B, e $\mathrm{D}$ as exportações contribuem em média com $30 \%$ no faturamento anual. $\mathrm{Na}$ empresa $\mathrm{E}$ esta contribuição é de cerca de $15 \%$. Este fato chama atenção para uma deficiência relativa da indústria nacional, pois, enquanto as multinacionais dominam alguns mercados no Brasil, como por exemplo, o de tratores, a indústria nacional de MIAs tem pouca representatividade no mercado mundial.

A adoção de sistemas de gestão da qualidade com certificação ISO-9001 é um fenômeno relativamente recente nessas empresas. Quatro das empresas já são certificadas (A, B, D, E) e a principal razão da implantação do $S G Q$, e de sua certificação, foi a exigência de clientes, particularmente do mercado externo.

A empresa $\mathrm{C}$ tem características peculiares em comparação às demais. Nesta empresa as exportações são responsáveis por $50 \%$ do faturamento, porém isso não representa que $\mathrm{C}$ seja um benchmarking no setor. A alta contribuição das exportaçôes se deve à natureza dos produtos que a empresa fabrica, que são equipamentos voltados predominantemente para beneficiamento de grãos e cereais, principalmente café. Esta empresa não buscou obter nenhum tipo de certificação, pois seus clientes ainda não exigiram. 
Tabela 1 - Perfil das empresas

\begin{tabular}{|c|c|c|c|c|c|}
\hline $\begin{array}{c}\text { Característica } \\
\text { Analisada }\end{array}$ & Empresa A & Empresa B & Empresa C & Empresa D & Empresa E \\
\hline $\begin{array}{c}\text { Tipo de } \\
\text { administração }\end{array}$ & Familiar & Familiar & Patronal & $\begin{array}{l}\text { Transição (passando } \\
\text { de familiar a patronal) }\end{array}$ & $\begin{array}{c}\text { Transição } \\
\text { (passando de familiar } \\
\text { a patronal) }\end{array}$ \\
\hline $\begin{array}{l}\text { Quantidade de } \\
\text { funcionarios }\end{array}$ & 2000 & 1600 & $\begin{array}{c}\text { Entre } \\
500 \text { a } 700\end{array}$ & 900 & Entre 500 a 600 \\
\hline $\begin{array}{c}\text { Número de plantas/ } \\
\text { unidades }\end{array}$ & 2 & 1 & 2 & 1 & 2 \\
\hline $\begin{array}{l}\text { Faturamento } \\
\text { médio anual } \\
\text { (milhōes de reais) }\end{array}$ & Superior a 100 & $\begin{array}{c}\text { Entre } \\
75 \text { e } 100\end{array}$ & $\begin{array}{l}\text { Entre } \\
30 \text { a } 50\end{array}$ & Superior a 100 & Superior a 100 \\
\hline $\begin{array}{l}\text { Contribuição da } \\
\text { venda de novos } \\
\text { produtos no } \\
\text { faturamento }\end{array}$ & $\begin{array}{c}\text { Entre } \\
20 \text { a } 40 \%\end{array}$ & $\begin{array}{c}\text { Entre } \\
50 \text { a } 60 \%\end{array}$ & $\begin{array}{c}\text { Entre } \\
20 \text { a } 30 \%\end{array}$ & Entre 20 a $30 \%$ & Entre 20 a $40 \%$ \\
\hline $\begin{array}{l}\text { Contribuição das } \\
\text { exportaçôes no } \\
\text { faturamento }\end{array}$ & $30 \%$ & $30 \%$ & $50 \%$ & $35 \%$ & $15 \%$ \\
\hline Certificações & ISO-9000 & ISO-9000 & Não possui & ISO-9000 & ISO-9000 \\
\hline
\end{tabular}

\subsection{CARACTERÍSTICAS DA GESTÃO DO PDP}

\subsubsection{Tipos de projetos e produtos}

Observou-se a presença predominante, no projeto dos produtos, de sistemas e subsistemas mecânicos. Tais sistemas são totalmente desenvolvidos internamente pelas 5 empresas. Porém tanto a A quanto a $B$ também utilizam tecnologias hidráulica, pneumática, eletrônica, elétrica e de software. A empresa C é a única que utiliza tecnologia térmica, o que é justificado pela predominância na empresa de produtos voltados para o processamento de grãos, especialmente café, além da elétrica, eletrônica e hidráulica. A empresa D utiliza tecnologias elétrica, hidráulica e pneumática.

A predominância dos sistemas mecânicos é tradicional nessa indústria, porém percebe-se um aumento na incorporação de tecnologias mais avançadas nos equipamentos, pois isso vem se tornado um fator de competitividade na conquista dos clientes. Isso se observa nas grandes feiras do setor, onde é cada vez maior o lançamento de produtos com alta tecnologia, sendo que uma forte tendência é a incorporação de instrumentos GPS e de sensores e controles microeletrônicos.

\subsubsection{Recursos do PDP}

A porcentagem de funcionários atuando diretamente no PDP é relativamente baixa, em nenhuma das empresas ultrapassa $10 \%$ do quadro de funcionários. Em média 4,5\% dos funcionários participam do PDP, porém apenas uma das empresas considera que a quantidade baixa de pessoas envolvidas com o PDP é um fator limitante para a sua capacidade de realização de projetos.

\subsubsection{Equipes de projeto}

Em todas as cinco empresas o desenvolvimento de produtos é conduzido por equipes. Os membros dessas equipes são permanentes (as equipes são formadas sempres pelas mesmas pessoas) nas empresas $\mathrm{B}, \mathrm{C}$ e E, e variam ao longo da evolução do projeto nas empresas A e D. As empresas A e $\mathrm{D}$ organizam sua equipes por projeto, de modo que ao fim de cada projeto as equipes se dissolvem e as pessoas retornam às suas funçôes rotineiras. 
Um problema comum na estrutura organizacional por projeto é a dificuldade de realocar e integrar as pessoas ao término de um projeto, porém essas empresas não relataram a existência deste problema, principalmente porque tão logo termina o projeto de um produto já existem outros para serem realizados. Assim, apesar de não existir em todas as empresas um departamento exclusivo para desenvolvimento de produtos, as pessoas alocadas para trabalharem com desenvolvimento de produtos são sempre as mesmas. As pessoas que compóem uma equipe de projeto podem mudar ao longo do projeto, mas é sempre o mesmo conjunto de pessoas trabalhando com desenvolvimento de produto.

As empresas que trabalham com equipes de projeto organizadas matricialmente são também aquelas com o menor quadro de funcionários no total, ou seja, as empresas $\mathrm{C}$ e E, o que dificulta que as mesmas mantenham pessoal exclusivo para o PDP. Como já mencionado anteriormente, para a empresa E esse fato representa um obstáculo, pois nem sempre há um número de pessoas suficientes para que o PDP alcance o nível de desempenho desejado pela direção da empresa e, mesmo para o cumprimento dos prazos impostos pelo mercado, como, por exemplo, conseguir lançar o produto durante a safra de determinada cultura ou numa determinada feira de agronegócios.

Todas as equipes de projeto, nessas empresas, são conduzidas por um líder. Nas empresas A e D são indicados pelo gerente da área ou pela diretoria na qual o PDP esta inserido. Nas empresas $\mathrm{B}$ e $\mathrm{E}$ o líder de projeto é indicado pela alta administração, e na C o líder dos projetos normalmente é um dos diretores da empresa.

\subsubsection{Estrutura e procedimentos}

Apenas a empresa $C$ não possui um conjunto de procedimentos formalizados que definem como as atividades do PDP devem ser realizadas. Essa característica coincide com o fato dela ser também a única que não possui a certificação ISO-9001.

As fontes de novas idéias também são comuns nas empresas estudadas, todas buscam seus clientes usuários finais como a principal fonte de novas idéias, sendo que a participação em feiras e exposições também são consideradas importantes fontes de novas idéias para as empresas A, B e D.
Somente a empresa E cita os concorrentes como fonte de novas idéias.

Essas fontes de novas idéias são responsáveis pelo grande número de produtos desenvolvidos anualmente, conferindo ao setor uma característica de desenvolver grande numero de produtos customizados, o que tem ligação com a vasta extensão territorial e diversidade de características geográficas e topográficas do país, exigindo que o PDP seja flexível o suficiente para atender clientes de todas as regiōes do país.

Entre as empresas que têm certificação ISO 9001, as empresas A, D e E utilizam procedimentos, que na bibliografia são conhecidos como gates review, que são momentos de avaliação técnica e econômica das atividades que estão sendo realizadas no projeto. A empresa A avalia o cumprimento das metas e prazos, a qualidade do projeto, a viabilidade econômica e técnica, atratividade do projeto, custo de desenvolvimento, adequação do produto ao mercado e as mudanças necessárias no projeto. A empresa D avalia a viabilidade econômica do projeto, qualidade do projeto, cumprimento de metas e prazos, mudanças necessárias no projeto original. A E avalia as especificações planejadas em relação às obtidas, cumprimento de metas e prazos e custo de desenvolvimento. Observa-se que é comum a todas as empresas a avaliação do cumprimento das metas e prazos.

A existência desses gates review possibilita que as empresas conheçam melhor o projeto e seu PDP e diminuam os riscos de investimentos no desenvolvimento de produtos que não consigam sucesso no mercado. Não é comum nessas empresas a existência de projetos interrompidos ao longo do PDP, porém ainda que existam prejuízos ao descontinuar um projeto, o prejuízo é maior ainda quando ao lançar o novo produto o mesmo não traz retorno planejado pela empresa.

É comum em todas as empresas a realização das atividades: determinação dos requisitos dos clientes; avaliação da viabilidade técnica e econômica do projeto; planejamento de recursos; a tradução do conceito do produto em especificações, escolha dos componentes, estilo e layout; seleção dos fornecedores; elaboração e construção de protótipos; realização de testes com protótipos. $\mathrm{Ou}$ seja, percebe-se que ainda faz parte do perfil dessas empresas considerarem que o PDP se restringe apenas à fase de desenvolvimento propriamente dito, desconsiderando o pré-desenvolvimento e o 
pós-desenvolvimento. Em outros setores industriais, é comum que as empresas considerem a Assistência Técnica como parte do PDP, pois ao desvincular a assistência técnica muitas vezes os responsáveis pelo processo podem perder dados relativos ao mau funcionamento dos mesmos, que acaba acarretando na não satisfação do cliente. Assim a chance de fracasso de um novo produto é alta, ou seja, isso serve como indicador da capacitação do PDP para a empresa.

\subsubsection{Métodos e técnicas de suporte}

A utilização de ferramentas de apoio às atividades do PDP serve como um indicador do grau de maturidade e entendimento das empresas em relação ao PDP com um todo. $\mathrm{O}$ baixo grau de conhecimento de tais facilitadores no setor demonstra que ainda há uma predominância na interpretação do PDP como sendo apenas o desenvolvimento do projeto de engenharia. Percebe-se que as empresas estudadas conhecem ferramentas que auxiliam no desenho dos novos produtos, como é o caso do CAD, o que confirma que o foco do PDP dessas empresas é em aspectos técnicos do projeto e do produto.

A empresa $\mathrm{C}$ que utiliza somente o CAD e CAM, dentre as diversas técnicas e métodos de apoio ao PDP recomendados na bibliografia da área, atua basicamente em mercados de países em desenvolvimento. Nas demais empresas, que estão tentando se inserir em mercados de países desenvolvidos, percebe-se uma tentativa de aplicação de outras ferramentas de apoio ao PDP, como é o caso com maior intensidade da empresa $A$, que também utiliza métodos tais como as ferramentas estatisticas para a qualidade, FMEA ( análise do efeito e modo de falha), DFMA ( projeto para manufatura e montagem), CAPP ( computer aided process planning) etc

Todas as empresas utilizam algum tipo de indicador de desempenho para avaliar o PDP. Os indicadores mais freqüentemente utilizados são: taxa de reparo dos novos produtos, principalmente durante o período de garantia (Empresas A, C, $\mathrm{D}$ e E); taxa de devolução dos produtos (A, B, $\mathrm{C}$ e D), custo de desenvolvimento do projeto (A, $\mathrm{C}, \mathrm{D}$ e $\mathrm{E})$; taxa de retorno sobre o investimento $(\mathrm{A}, \mathrm{C}$ e $\mathrm{D})$. Outros indicadores são utilizados por no máximo duas empresas estudadas como, por exemplo, a porcentagem do faturamento que vem de novos produtos $(\mathrm{C}$ e $\mathrm{D})$, participação dos novos produtos no mercado (A e C), tempo para desenvolvimento e lançamento dos novos produtos (D e E).

Todos os indicadores utilizados pelas empresas relacionam-se a parâmetros como qualidade do produto desenvolvido, tempo de conclusão do projeto e custo para desenvolvimento. No entanto, observa-se uma predominância de indicadores econômicos, demonstrando a grande preocupação com a lucratividade dos produtos. Esse foco na avaliação econômico-financeira não é prejudicial à avaliação do PDP quando, além do fator rentabilidade, existe também um foco de avaliação da qualidade dos produtos e da satisfação dos clientes. É de se esperar que, à medida que melhoram esses índices, também melhorem os indicadores econômicos. O foco em indicadores econômicos reflete um planejamento estratégico mais voltado para resultados de curto prazo.

Se comparado com outros setores industriais, o tempo de desenvolvimento de novos produtos da indústria de MIAs é extremamente curto. Quando ocorre o atraso no lançamento de um novo produto, além de se ter esperar até a próxima safra, existe a possibilidade de um concorrente lançar um produto similar, podendo-se incorrer em prejuízos, pois as MIAs duram por muito tempo, ou seja, pode ser que o cliente que adquiriu uma MIAs do concorrente só volte a precisar de outra similar após cerca de 10 anos.

\subsubsection{Principais problemas percebidos pelas empresas}

Os custos de desenvolvimento representam problemas para as empresas $\mathrm{C}$ e $\mathrm{D}$, para a $\mathrm{C}$ o custo de desenvolvimento é alto, enquanto na empresa $\mathrm{D}$ há escassez de recursos financeiros para investir nos projetos.

A empresa $\mathrm{E}$ enfrenta muitos problemas relacionados à gestão de pessoas, tendo que atuar com equipes de projeto relativamente pequenas, além disso a empresa tem problemas para gerenciar o fluxo de informações entre a área de Engenharia, responsável pelo PDP, e as outras áreas da empresa.

Existem em todas as empresas problemas relacionados ao tempo de desenvolvimento pois, caso ocorra atraso na data prevista de lançamento do produto é comum que tenha que se esperar até 
a próxima safra para o qual o produto se destina para lança-lo. Além disso, a situação se agrava quando um concorrente lança um similar, pois ao perder de vender uma MIA devido ao atraso no lançamento é possível que o cliente que comprou do concorrente só volte a precisar de outra máquina depois de 10 anos.

\subsection{NÍVEL DE MATURIDADE DO PDP}

De acordo com a classificação de níveis de maturidade, proposta por Rozenfeld et al (2005), avalia-se que a empresa $\mathrm{C}$ é a que se encontra no nível mais básico de maturidade: muitas vezes as características dos produtos a serem desenvolvidos são determinadas pela própria empresa, na etapa de projeto informacional os requisitos dos clientes são considerados, porém as atividades do PDP limitam-se às macro-fases de pré-desenvolvimento e de desenvolvimento, não são realizadas atividades de pós-desenvolvimento, os métodos e técnicas utilizados durante o PDP são voltadas essencialmente para atividades de desenho e prototipagem. Em relação aos indicadores de desempenho que a empresa utiliza, ainda que sejam em grande número, todos são utilizados informalmente e são utilizados principalmente pelo departamento financeiro da empresa, nem sempre chegando tais informaçōes ao PDP.

Em escala crescente do nível de maturidade em seguida vem a empresa B: seu PDP também está no nível básico, no entanto a mesma considera, desde o início do processo de desenvolvimento, os requisitos dos clientes na definição dos requisitos do produto. Além disso, essa empresa se prepara para o lançamento do produto no mercado, e também já incorpora uma atividade do pós-desenvolvimento ao seu PDP, que consiste no acompanhamento, pela equipe de projeto, do desempenho do produto em uso. Percebe-se também uma evolução na aplicação de ferramentas de apoio utilizadas, que vão além das atividades de prototipagem e que incorporam técnicas relativas a avaliação da qualidade, custos e de adequação ao processo produtivo. Essa empresa, porém, ainda utiliza poucos indicadores de desempenho e não realiza gates reviews ao longo do processo, o que demonstra uma lacuna nas atividades de controle do projeto.

O PDP das empresas D e E estão em níveis de maturidade equivalentes, em evolução do nível básico para o intermediário. Ambas as empresas já têm suas atividades de desenvolvimento padronizadas com a utilização de métodos de apoio. Além disso, ambas já têm definido e sistematizado a realização de gates reviews ao término de cada atividade, porém as atividades de pós-desenvolvimento ainda são realizadas de modo deficiente.

A empresa A pode ser considerada o benchmarking para o grupo das empresas estudadas, seu PDP está no nível controlado, a mesma realiza de maneira padronizada todas as atividades de desenvolvimento do projeto. Além disso, a utilização dos gates reviews se dá de maneira efetiva e os indicadores de desempenho servem como base para a tomada de decisões e de ações de melhoria. A tabela 2 busca sintetizar a gestão do PDP nas empresas estudadas.

Tabela 2 - Síntese da gestão do PDP

\begin{tabular}{|c|c|c|c|c|c|}
\hline Característica & Empresa A & Empresa B & Empresa C & Empresa D & Empresa E \\
\hline $\begin{array}{c}\text { Porcentagem de } \\
\text { funcionários envolvidos } \\
\text { com o PDP }\end{array}$ & $8,5 \%$ & $3 \%$ & $1 \%$ & $2 \%$ & $8 \%$ \\
\hline $\begin{array}{c}\text { Existência de equipes } \\
\text { de projeto }\end{array}$ & $\begin{array}{c}\text { Sim, não são } \\
\text { fixas }\end{array}$ & Sim e são fixas & Sim e são fixas & $\begin{array}{c}\text { Sim, não são } \\
\text { fixas }\end{array}$ & Sim e são fixas \\
\hline $\begin{array}{c}\text { Áreas da empresa } \\
\text { presentes nas equipes } \\
\text { de projeto }\end{array}$ & $\begin{array}{c}\text { Pesquisa e } \\
\text { desenvol- } \\
\text { vimento, } \\
\text { engenharia. }\end{array}$ & $\begin{array}{c}\text { Engenharia } \\
\text { de produto, } \\
\text { engenharia } \\
\text { de processo, } \\
\text { qualidade e } \\
\text { logística. }\end{array}$ & $\begin{array}{c}\text { Diretoria, } \\
\text { projetistas }\end{array}$ & $\begin{array}{c}\text { Engenharia } \\
\text { de produto, } \\
\text { engenharia } \\
\text { de processo, } \\
\text { engenharia de } \\
\text { desenvolvimento } \\
\text { de produto }\end{array}$ & $\begin{array}{c}\text { Engenharia } \\
\text { de projeto, } \\
\text { engenharia } \\
\text { de produto, } \\
\text { Assistência } \\
\text { técnica (campo) }\end{array}$ \\
\hline
\end{tabular}




\begin{tabular}{|c|c|c|c|c|c|}
\hline $\begin{array}{c}\text { Organização das } \\
\text { equipes de projeto }\end{array}$ & Por projeto & Funcional & Funcional & Por projeto & $\begin{array}{c}\text { Funcional e } \\
\text { matricial }\end{array}$ \\
\hline $\begin{array}{c}\text { Número de projetos } \\
\text { conduzidos por uma } \\
\text { equipe }\end{array}$ & 1 & 1 & 2 & 6 & 5 \\
\hline $\begin{array}{c}\text { Indicação do líder da } \\
\text { equipe }\end{array}$ & $\begin{array}{c}\text { Indicado pelo } \\
\text { gerente da } \\
\text { engenharia }\end{array}$ & $\begin{array}{c}\text { Indicado pela } \\
\text { alta adminis- } \\
\text { tração }\end{array}$ & $\begin{array}{c}\text { O líder é o } \\
\text { diretor }\end{array}$ & $\begin{array}{c}\text { Indicado } \\
\text { pelo gerente } \\
\text { de desenvol- } \\
\text { vimento de } \\
\text { produto }\end{array}$ & $\begin{array}{c}\text { Indicado pela } \\
\text { alta adminis- } \\
\text { tração }\end{array}$ \\
\hline $\begin{array}{c}\text { Porcentagem de pessoas } \\
\text { envolvidas no PDP que } \\
\text { possuem formação em } \\
\text { nível superior }\end{array}$ & $85 \%$ & $16 \%$ & $100 \%$ & $\begin{array}{c}\text { Dados não } \\
\text { fornecidos }\end{array}$ & $20 \%$ \\
\hline
\end{tabular}

\section{CONSIDERAÇÕES FINAIS}

De modo geral, as cinco empresas estão profissionalizando sua gestão. Ainda que o capital das empresas mantenha sua origem familiar, as mesmas têm contratado profissionais com formação superior e experiência em outros setores para assumirem cargos executivos de diretoria. Essas mudanças coincidem com a busca de novos mercados e apontam para o momento de transição vivido pelo setor, passando de empresas predominantemente conservadoras e com produtos tradicionais, para empresas mais inovadoras, aumentando a freqüência de lançamento de novos produtos.

O modo de gestão familiar tradicional, e a falta de uma visão estratégica, têm como implicações à não existência de preocupação com um planejamento adequado do portfolio de produtos e de projetos das empresas. Freqüentemente os projetos são iniciados por sugestôes pouco fundamentadas e analisadas, e têm como foco da atenção o lançamento e a exposição dos produtos nas grandes feiras do setor agroindustrial, privilegiando-se muitas vezes o tempo (rapidez) para conseguir expor o produto em prejuízo da qualidade do projeto e do produto.

Entretanto, as pressões do ambiente competitivo e de regulamentações têm feito com que essas empresas se preocupem mais com as suas estratégias de produto e com a gestão do conjunto de projetos e também com o acompanhamento e incorporação de inovações tecnológicas, nos produtos e nos sistemas de produção, como meios potenciais para alavancar as exportações. As exportações ainda representam pouco no faturamento geral das empresas.

A busca por sistemas de certificação da qualidade nos anos de 2003-2005 foi marcante nessas empresas, visto que 3 das 5 empresas obtiveram a certificação ISO 9001 nesse período. Das outras duas: uma é certificada desde 1994 e a outra, que é a única não certificada, não tem previsão de obtenção desta certificação.

As linhas de produtos de todas as empresas são diversificadas e atendem a diversas culturas agrícolas. Já em relação às atividades para as quais estão voltadas percebe-se que, em média, elas fabricam produtos para pelo menos três etapas produtivas, buscando-se assim estratégias de produto e de mercado que permitam um faturamento melhor distribuído ao longo do ano, amenizando os efeitos das sazonalidades do setor.

Em todas as empresas os produtos apresentam como base principal a tecnologia mecânica, porém já existem produtos sendo fabricados com maior incorporação de tecnologias elétrica, eletrônica, hidráulica, pneumática e de software. Essa última é a grande tendência do setor, o que contribui para aumentar a precisão nas operações dos equipamentos.

Em relação à visão sobre o PDP, percebe-se um perfil bastante heterogêneo entre as empresas. Há predominância de uma visão mais focada nos aspectos técnicos dos projetos dos novos produtos, tais como o projeto de engenharia, a realização de testes de desempenho técnico dos produtos e validação dos protótipos. 
Com base nessas informações sugere-se que as empresas, particularmente $\mathrm{B}, \mathrm{C}, \mathrm{D}$ e E, invistam e desenvolvam capacitação para melhorar a gestão estratégica e operacional do PDP, visualizando-o de maneira estratégica, articulando e integrando todas as atividades desse processo. Ou seja, não devem focar apenas o projeto de engenharia em si, mas também nas atividades de pesquisa de mercado, de desenvolvimento do processo produtivo, de lançamento do produto e de acompanhamento do desempenho do mesmo no mercado e na produção.

Com a incorporação de melhorias na gestão do PDP dessas empresas, um dos resultados esperados é a diminuição no tempo de desenvolvimento dos produtos, principalmente se ocorrer uma melhor integração interfuncional entre as diferentes áreas da empresa envolvidas nesse processo, e melhoria da qualidade do projeto, com redução da necessidade de mudanças de projeto com a conquente redução dos custos da não qualidade. Isso possibilitará que as atividades do PDP sejam realizadas, com maior confiabilidade, paralelamente nas diversas áreas envolvidas, não sendo necessário esperar que uma determinada atividade seja totalmente finalizada para que a posterior tenha início.

Recomenda-se que essas empresas que invistam na melhoria do seu processo de desenvolvimento de produto focando em todas as fases, desde o pré-desenvolvimento até o pós-desenvolvimento, principalmente com o uso de indicadores de desempenho focados nessas fases, e buscando uma maior integração entre as áreas funcionais envolvidas. Além disso, sugere-se o acompanhamento dos indicadores como base de referência na tomada de decisões.

É necessário que essas empresas tornem o seu processo de desenvolvimento mais ágil e eficaz, pois o sucesso de um novo implemento agrícola está diretamente ligado ao lançamento do mesmo no momento propício e adequado ao período anual da fase do processo agrícola a que se destina. Por exemplo, caso uma nova colheitadeira não seja disponibilizada, ou apresente problemas, no período da colheita, a empresa poderá ter que esperar mais um ano até que chegue o novo período de safra. Isso poderá representar significativas perdas no investimento no novo produto.

Além disso, é importante que o Brasil, seja por meio de políticas públicas ou por meio de entidades voltadas para o setor, incentive o desenvolvimento de tecnologias para esse setor, para que a indústria nacional se desenvolva, não apenas na capacidade de manufaturar máquinas e implementos agrícolas, mas também na geração de inovações tecnológicas ajudando na solução de problemas de competitividade da agricultura brasileira.

\section{BIBLIOGRAFIA}

ASSOCIAÇÃO BRASILEIRA DA INDÚSTRIA DE MÁQUINAS E EQUIPAMENTOS. Desempenho do Setor. Disponível em: www.anuarioabimaq.com.br. Acesso em 19 abril 2006.

CLARK, K.B.; WHEELWRIGHT, S.C. Revolutionizing product development: quantum leaps in speed, efficiency, and quality. New York: NY, 1992. $364 \mathrm{p}$.

INSTITUTO BRASILEIRO DE GEOGRAFIA E ESTATISTICA (IBGE) disponível em: <www. ibge.gov.br> Acesso em: 10 jan. 2005.

MOLIN, J. P. Desafios de mecanização. Cultivar máquinas, n. 5, p. 23-25, set/ out. 2001.

Pneu- Alta tecnologia para rodar no campo. Disponível em <http://www.revistarural.com.br/Edicoes/2004/Artigos/rev75_pneu.htm > Acesso em 11/07/2005.

PRASAD, B. Concurrent Engineering Fundamentals: integrated product and process organization, v.1. New Jersey: Prentice Hall International Series, 1996.

ROMANO, L. N. Modelo de Referência para o Processo de Desenvolvimento de Máquinas Agrícolas. 321p. Tese (Doutorado em Engenharia Mecânica) - Universidade Federal de Santa Catarina, Florianópolis: 2003.

ROZENFELD H. et al. Gestão de Desenvolvimento de Produtos - uma referência para a melhoria do processo. São Paulo: Saraiva, 2006.

SLACK, N. Vantagem competitiva em manufatura: atingindo competitividade nas operaçōes industriais. São Paulo, Atlas, 2. Edição 2002. 